\title{
Caribenols A and B, Sea Whip-Derived Norditerpenes with Novel Tricarbocyclic Skeletons
}

Xiaomei Wei, Ileana I. Rodríguez, Abimael D. Rodríguez, and Charles L. Barnes

Department of Chemistry, University of Puerto Rico, P.O. Box 23346, U.P.R. Station, San Juan, Puerto Rico 00931-3346 and Department of Chemistry, 123 Chemistry Building, University of Missouri-Columbia, Columbia, MO 65211, USA

\section{Supporting Information}

ORTEP drawing for Caribenol $A(\mathrm{~S} 2)$

Crossover Products Isolated from the Two Pseudopterogorgia elisabethae Chemotypes (S3)

Selected Norditerpenes Previously Isolated from Pseudopterogorgia elisabethae (S4)

Key ${ }^{1} \mathrm{H}$ and ${ }^{13} \mathrm{C}$ NMR Chemical Shifts Comparison of Caribenol B (2) and Amphilectolide (S5)

Plausible Biogenetic Pathways Leading to Some Norditerpenes Isolated from P. elisabethae (S6)

${ }^{1} H$ and ${ }^{13} C$ NMR Spectra of Caribenol $A$ in $C_{6} D_{6}(\mathrm{~S} 7)$

${ }^{1} H_{-}{ }^{1} H$ COSY Spectrum of Caribenol $A$ in $C_{6} D_{6}(\mathrm{~S} 8)$

$H M B C$ Spectrum of Caribenol $A$ in $C_{6} D_{6}(\mathrm{~S} 9)$

NOESY Spectrum of Caribenol $A$ in $C_{6} D_{6}(\mathrm{~S} 10)$

${ }^{1} \mathrm{H}$ and ${ }^{13} \mathrm{C} N \mathrm{NR}$ Spectra of Caribenol B in $\mathrm{CDCl}_{3}(\mathrm{~S} 11)$

Expansions of the ${ }^{13} C$ NMR Spectrum of Caribenol B in $\mathrm{CDCl}_{3}(\mathrm{~S} 12)$

${ }^{1} \mathrm{H}^{-}{ }^{1} \mathrm{H}$ COSY Spectrum of Caribenol B in $\mathrm{CDCl}_{3}(\mathrm{~S} 13)$

$\mathrm{HMBC}$ Spectrum of Caribenol B in $\mathrm{CDCl}_{3}(\mathrm{~S} 14)$

NOESY Spectrum of Caribenol B in $\mathrm{CDCl}_{3}(\mathrm{~S} 15)$ 


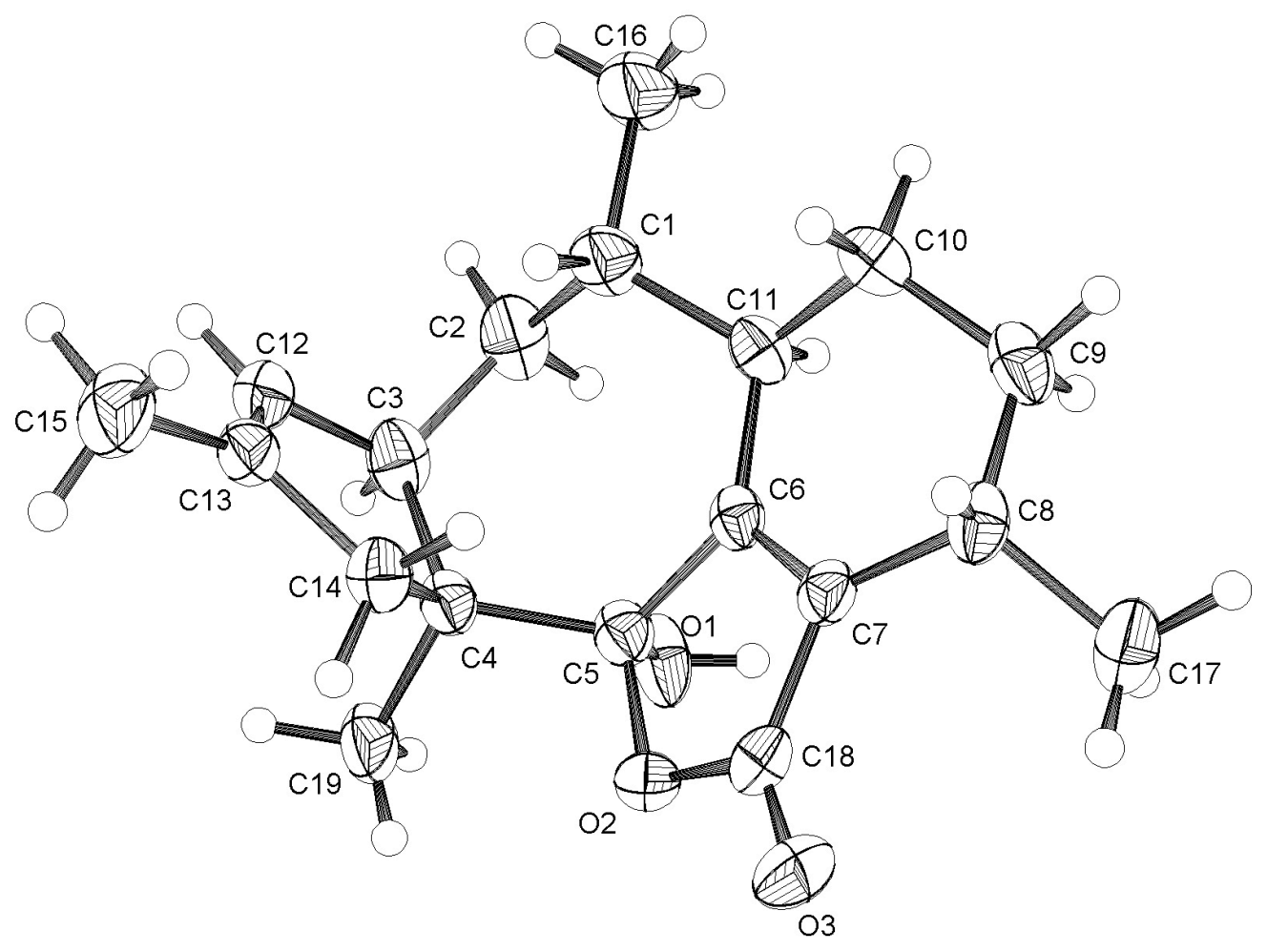

ORTEP drawing for Caribenol A 


\section{Crossover Products Isolated from the Two Pseudopterogorgia elisabethae Chemotypes.}

Chemotype I (Old Providence Island) was characterized by its massive production of pseudopterosins. Eleven new members of this profuse family of anti-inflammatory diterpeneglycosides were reported by us in $2004 .^{2}$ However, trace amounts of other known compounds previously isolated from chemotype II (San Andrés Island) were also detected within the extracts of chemotype I. The purification of a medium polar fraction of the hexane extract of $P$. elisabethae (chemotype I) by successive size exclusion chromatography (Bio-Beads ${ }^{\circledR}$ SX-3 in toluene), column chromatography (15 g silica gel in 8:2 chloroform-hexane), and HPLC (PolarBonded Cyano column in 97:3 hexane-isopropanol) led to the isolation of elisapterosin A (4.3 $\mathrm{mg})$, elisabanolide $(2.0 \mathrm{mg})$, and cumbiasin $\mathbf{C}(2.1 \mathrm{mg})$. Another compound that appears to be biogenetically related to other compounds isolated from chemotype II is ileabethoxazole. The latter metabolite is based on the known ileabethane carbon skeleton and contains the rare benzoxazole moiety (first detected from compounds isolated from chemotype II, namely, ileabethane and pseudopteroxazole. P. elisabethae from San Andrés Island is characterized by the presence of a complex array of secondary metabolites identified as diterpenoids based on a series of novel carbon skeletons that have been reported over the last decade. ${ }^{3}$ Some of these families of compounds include the elisabethanes, elisabanes, colombianes, sandresanes, cumbianes, and ileabethanes. It is rather curious that only two seco-pseudopterosins were isolated (in trace amounts) from the study of $P$. elisabethae colonies from San Andrés Island (chemotype II). 
Selected Norditerpenes Previously Isolated from Pseudopterogorgia elisabethae<smiles>C=C(C)C(=O)[C@]12C(=O)[C@H](C)CC[C@H]1[C@@H](C)C[C@H](C=C(C)C)[C@H]2C</smiles>

Elisabethin B<smiles>[R][C@]12OC(=O)C3=C1[C@@H](C)CC[C@H]3[C@@H](C)C[C@@H](C=C(C)C)[C@@]2(C)O</smiles>

Sandresolide $A: \mathrm{R}=\mathrm{H}$ Sandresolide $\mathrm{B}: \mathrm{R}=\mathrm{OH}$<smiles>C[C@H]1CC[C@H]2[C@@H](C)C[C@@H]3[C@@]2(C1=O)C(=O)[C@@]1(C)C(C)(C)OC(=O)[C@@]31C</smiles>

Elisabanolide<smiles>CC(=O)[C@]12OC(=O)C3=C1[C@@H](C)[C@@H](C)CC[C@H]3[C@@H](C)C[C@@H]2C</smiles>
4-acetyl-Amphilectolide 
Key ${ }^{1} \mathrm{H}$ and ${ }^{13} \mathrm{C}$ NMR Chemical Shifts Comparison of Caribenol B (2) and Amphilectolide*

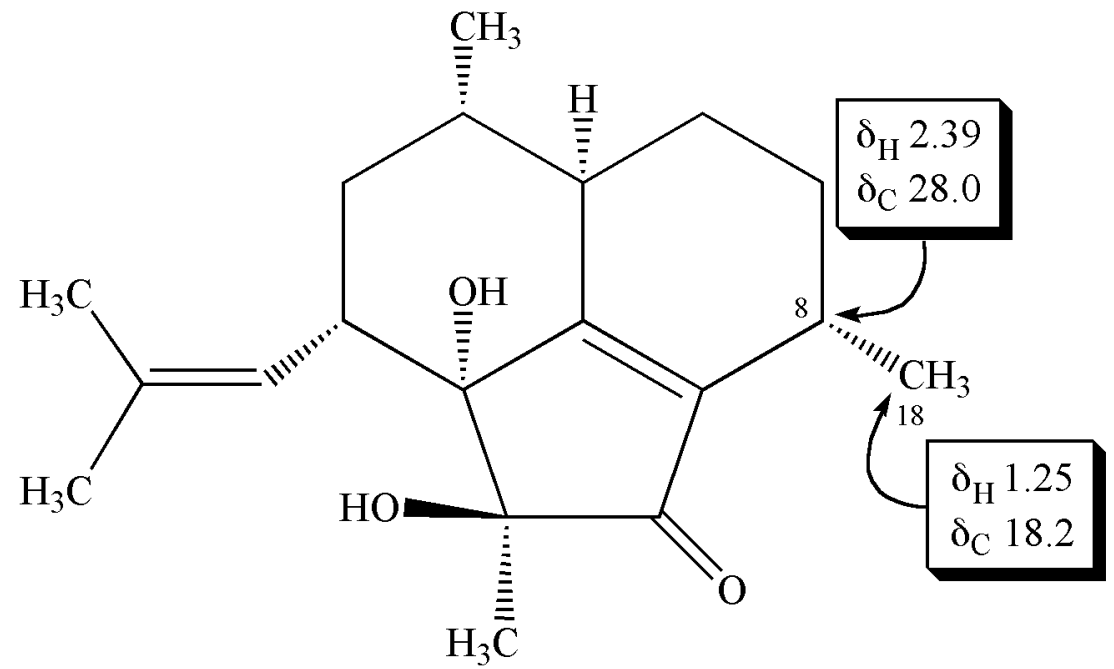

caribenol B (2)

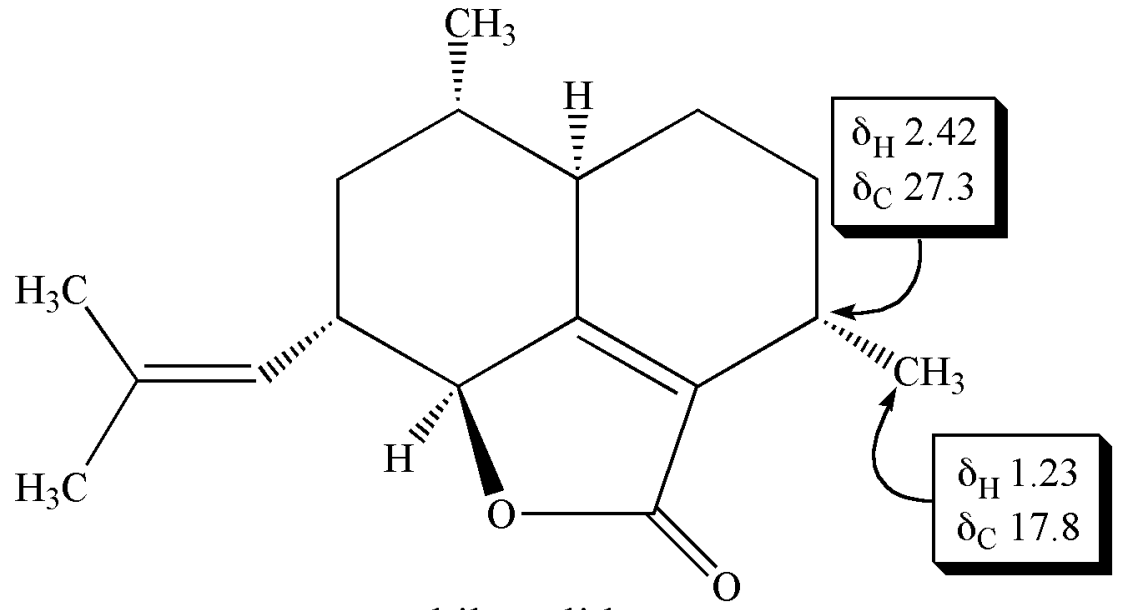

amphilectolide

* The NMR data for the two metabolites shown were acquired in $\mathrm{CDCl}_{3}$. 
Plausible biogenetic pathways leading to some norditerpenes isolated from $P$. elisabethae<smiles>CC(C)=C[C@H]1CC(C)[C@H]2CCC(C)c3c(O)c(O)c(C)c1c32</smiles><smiles>CC(C)=C[C@@H]1CC(C)C2CCC(C)C3=C2C1=C(O)C(=O)C3=O</smiles><smiles>CC[C@H]1C=C(C)C(C)CC1</smiles>

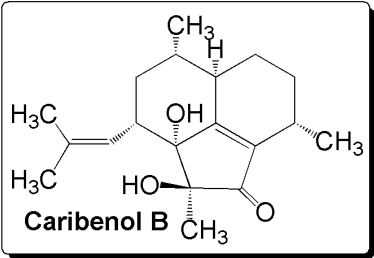

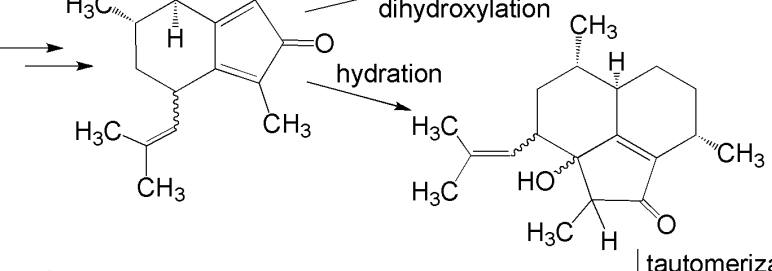

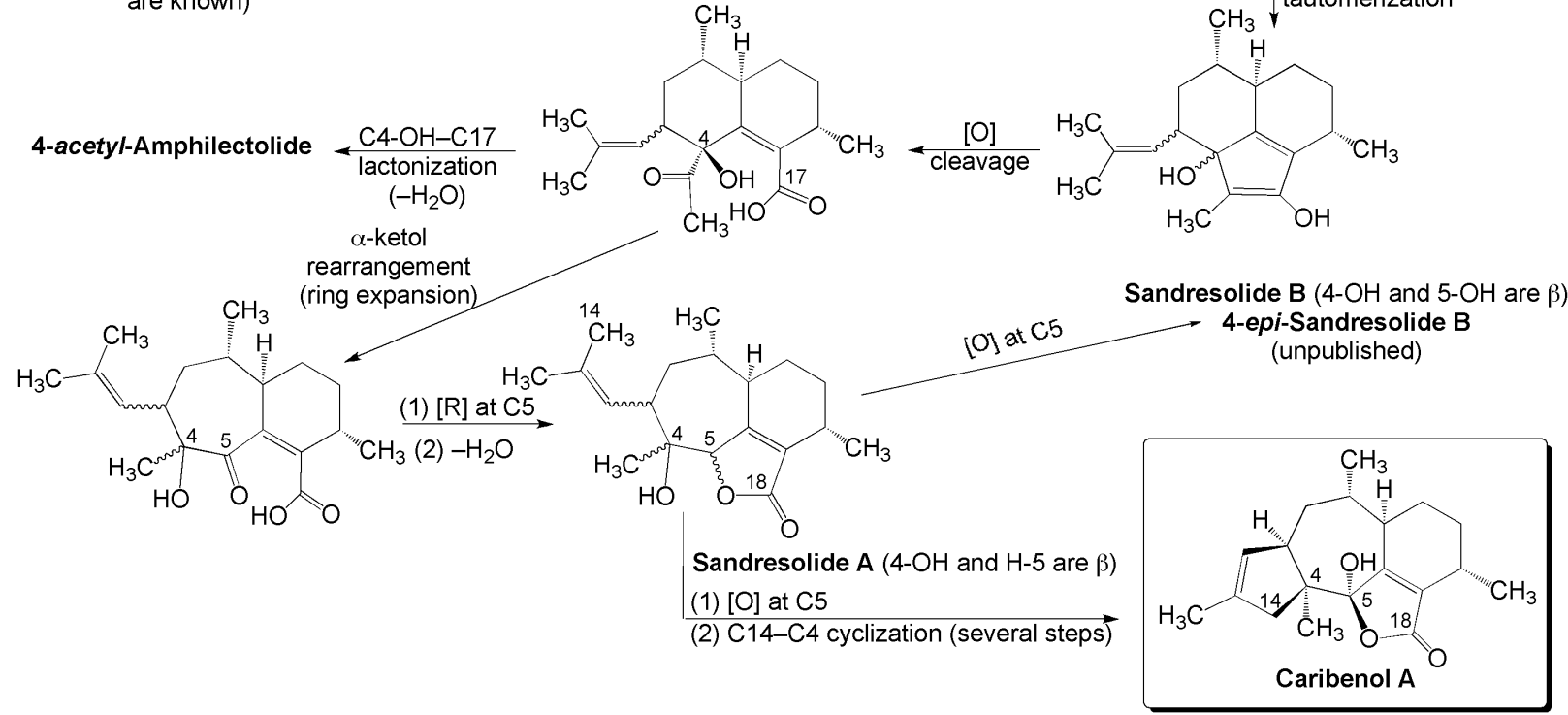




\section{${ }^{1} \mathrm{H}$ and ${ }^{13} \mathrm{C}$ NMR Spectra of Caribenol $\mathrm{A}$ in $\mathrm{C}_{6} \mathrm{D}_{6}$}
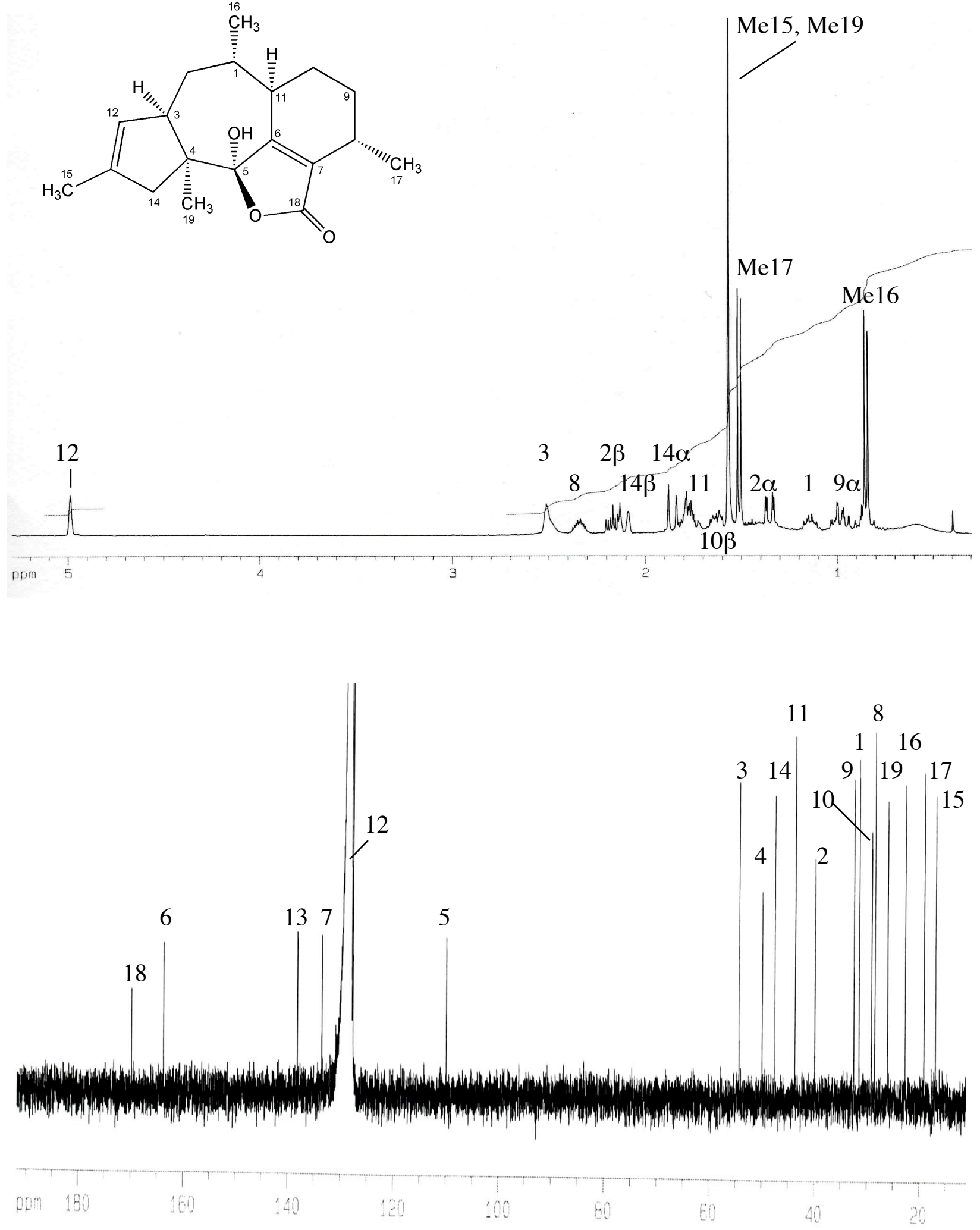


\section{${ }^{1} \mathrm{H}-{ }^{1} \mathrm{H}$ COSY Spectrum of Caribenol $\mathrm{A}$ in $\mathrm{C}_{6} \mathrm{D}_{6}$}

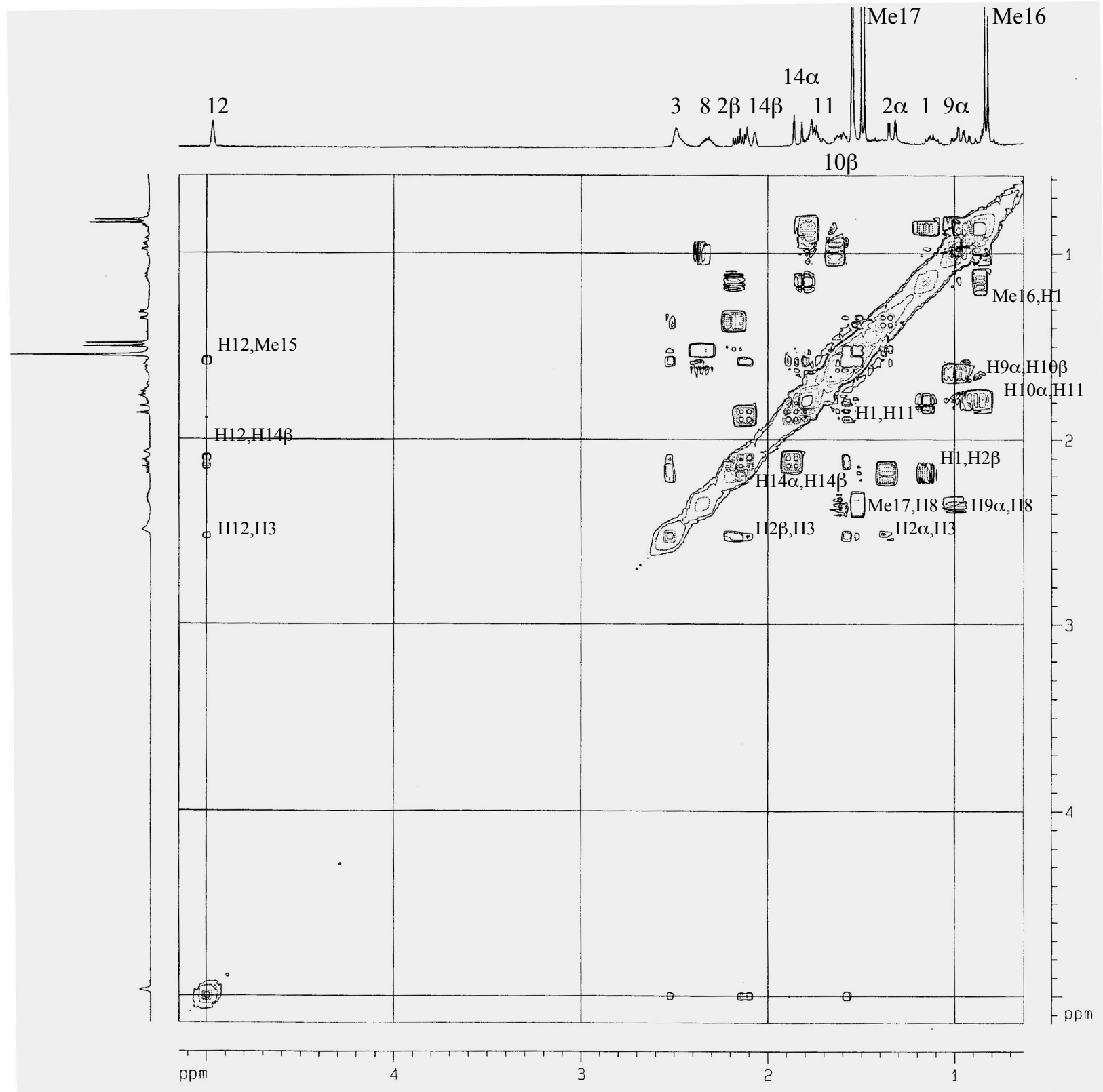


HMBC Spectrum of Caribenol $A$ in $C_{6} D_{6}$

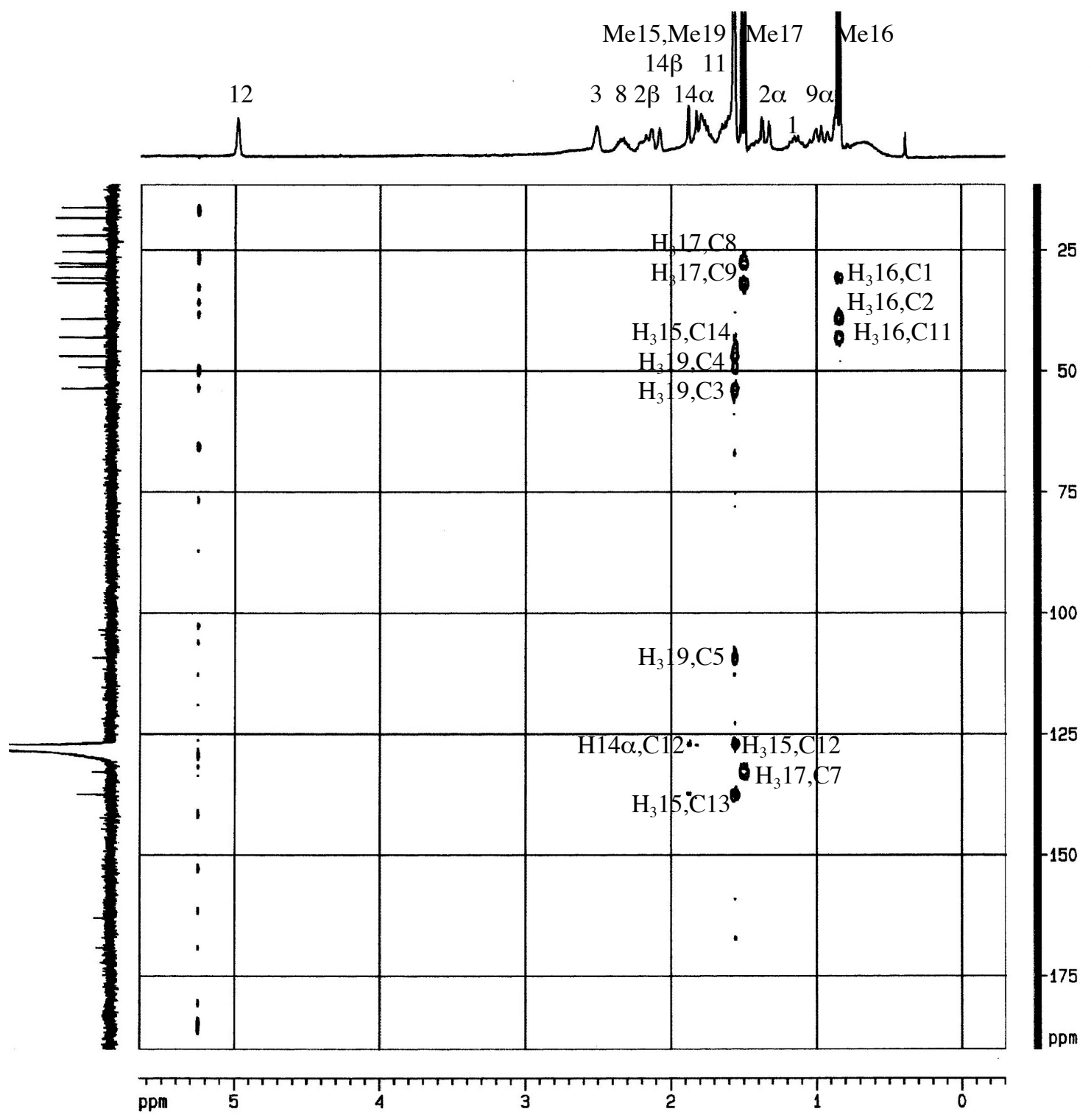


NOESY Spectrum of Caribenol $A$ in $C_{6} D_{6}$

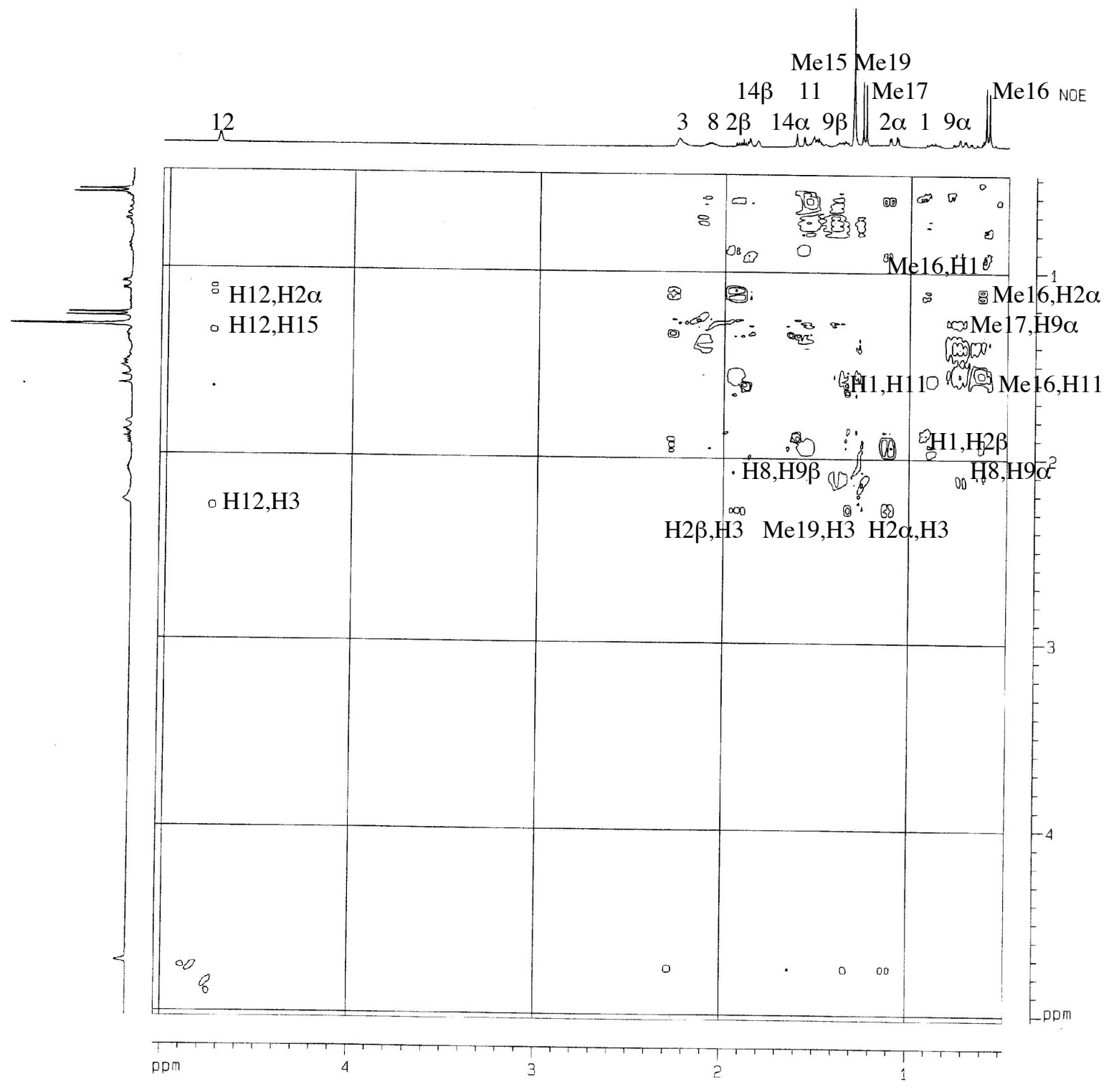


${ }^{1} \mathrm{H}$ and ${ }^{13} \mathrm{C}$ NMR Spectra of Caribenol $\mathrm{B}$ in $\mathrm{CDCl}_{3}$

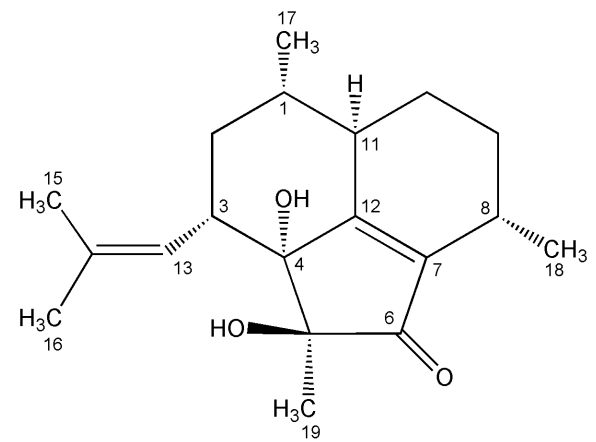

Me15 Me19
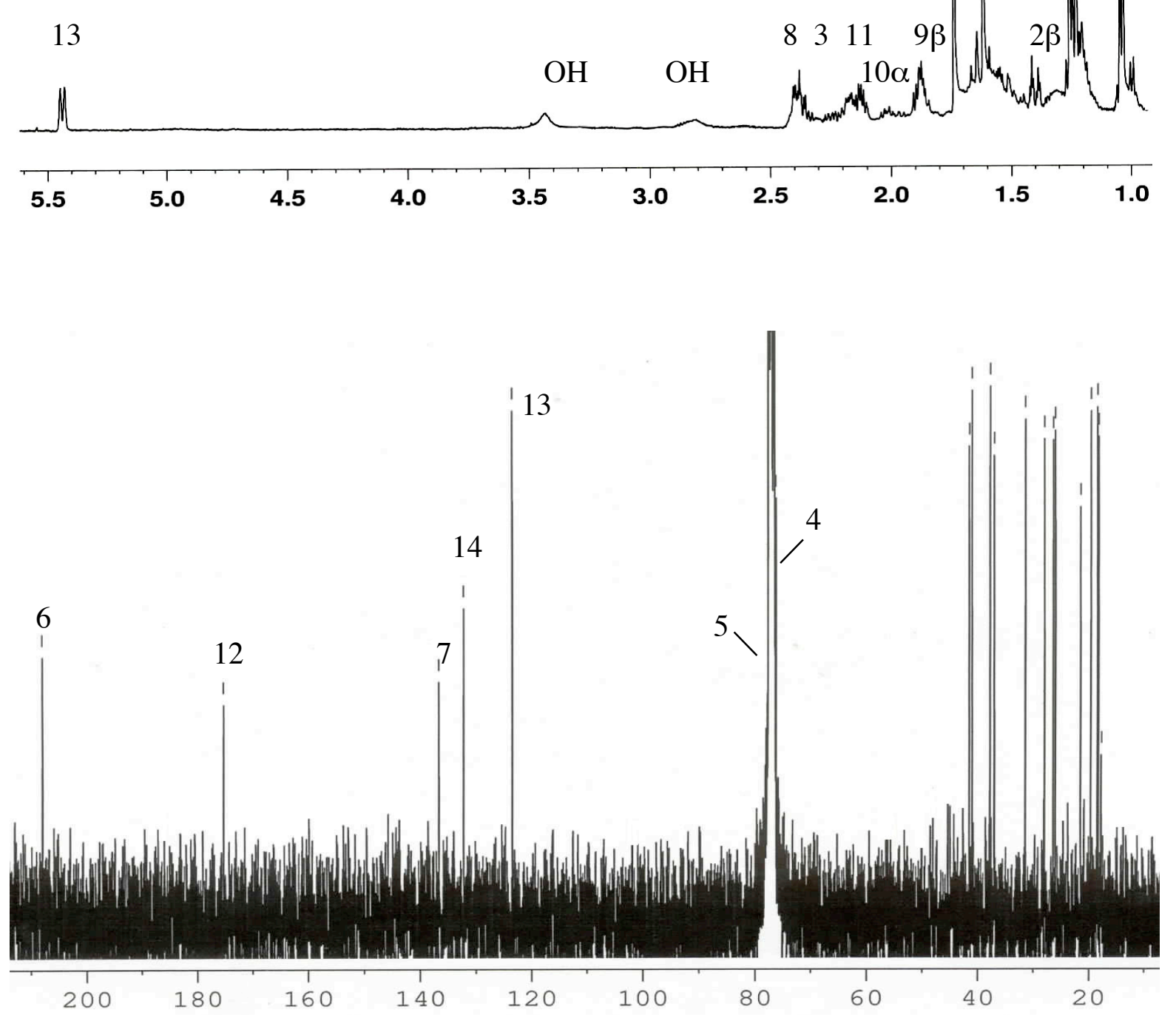
Expansions of the ${ }^{13} \mathrm{C}$ NMR Spectrum of Caribenol $\mathrm{B}$ in $\mathrm{CDCl}_{3}$
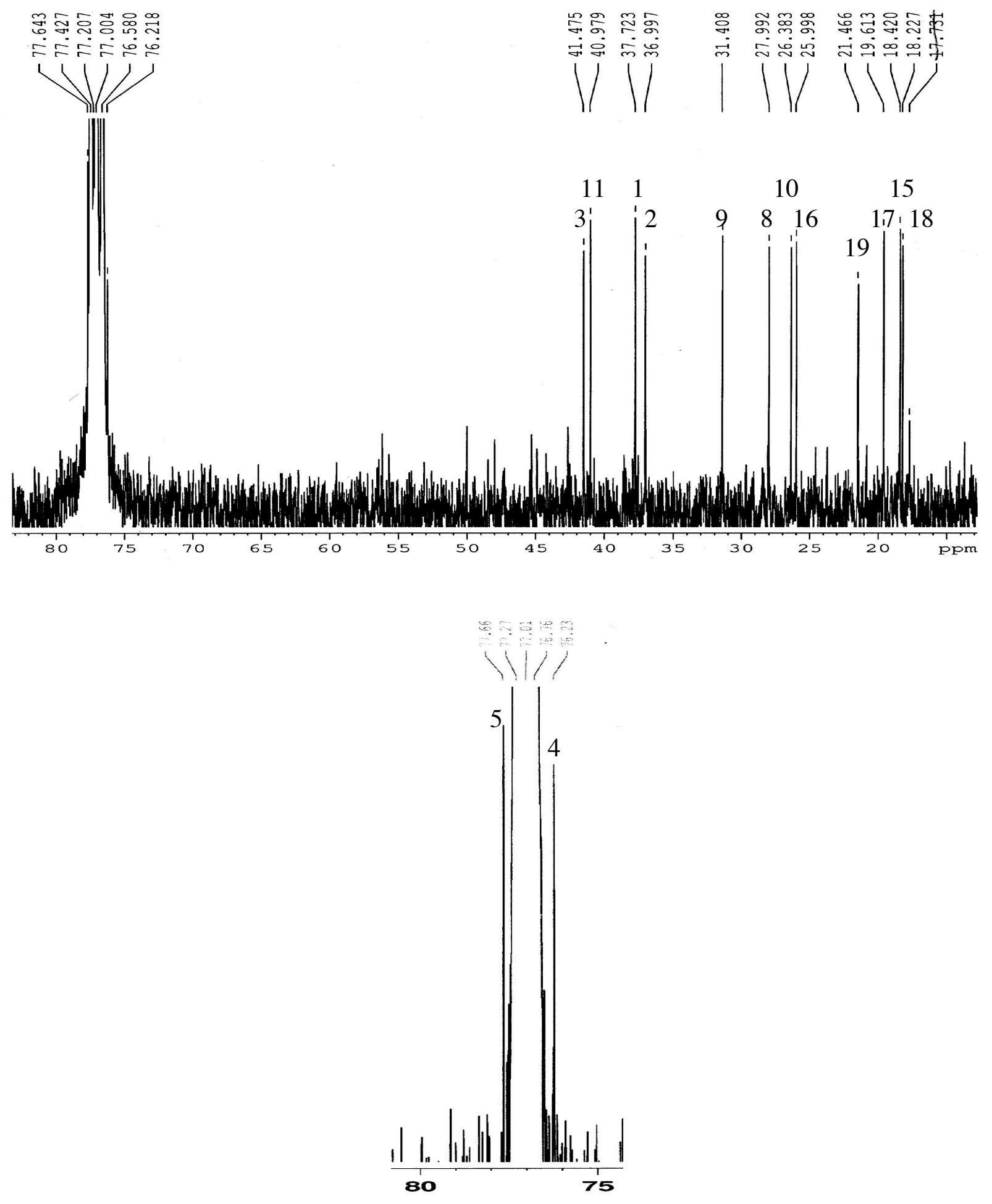


\section{${ }^{1} \mathrm{H}-{ }^{1} \mathrm{H}$ COSY Spectrum of Caribenol $\mathrm{B}$ in $\mathrm{CDCl}_{3}$}

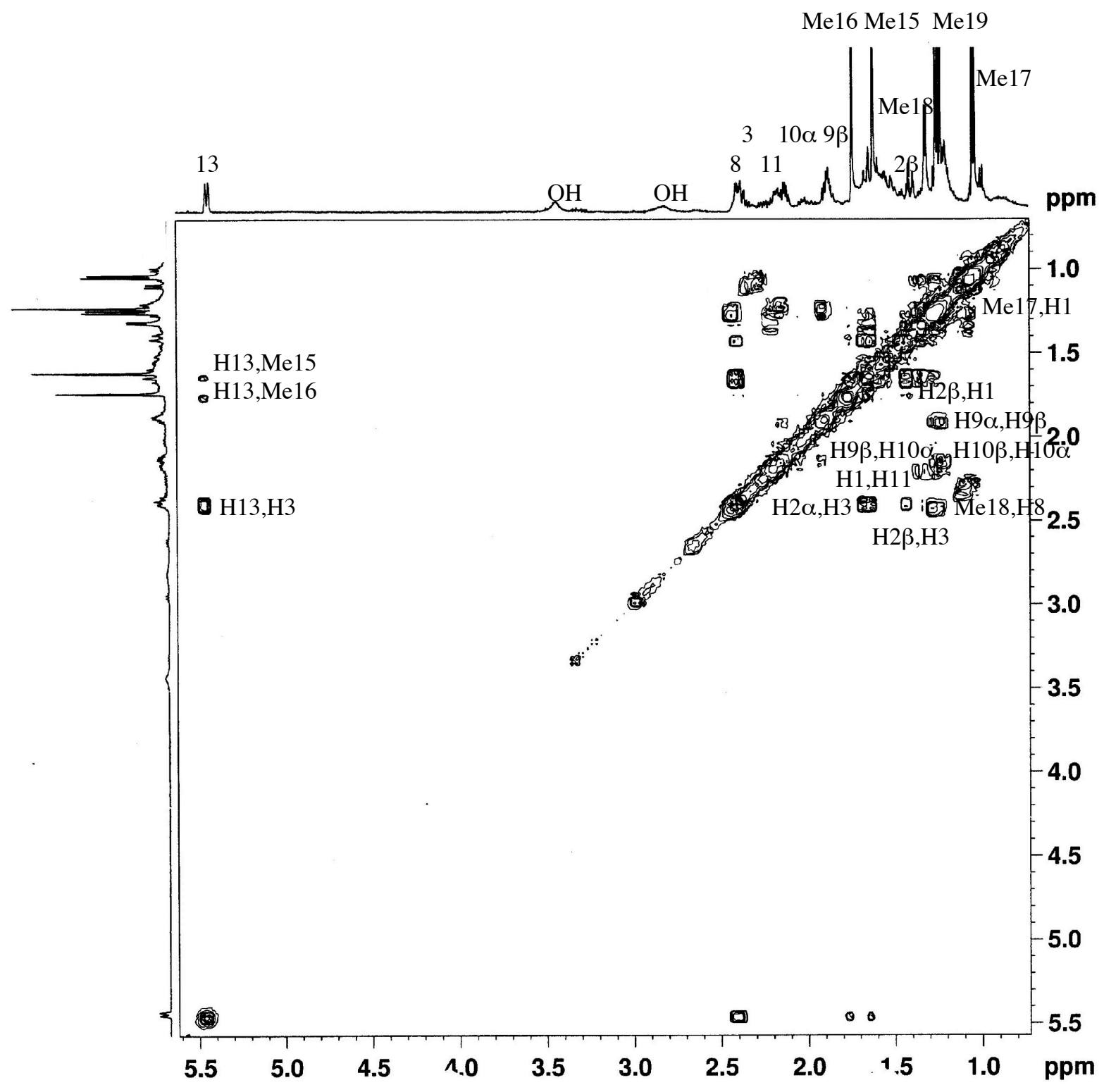


$\mathrm{HMBC}$ Spectrum of Caribenol $\mathrm{B}$ in $\mathrm{CDCl}_{3}$

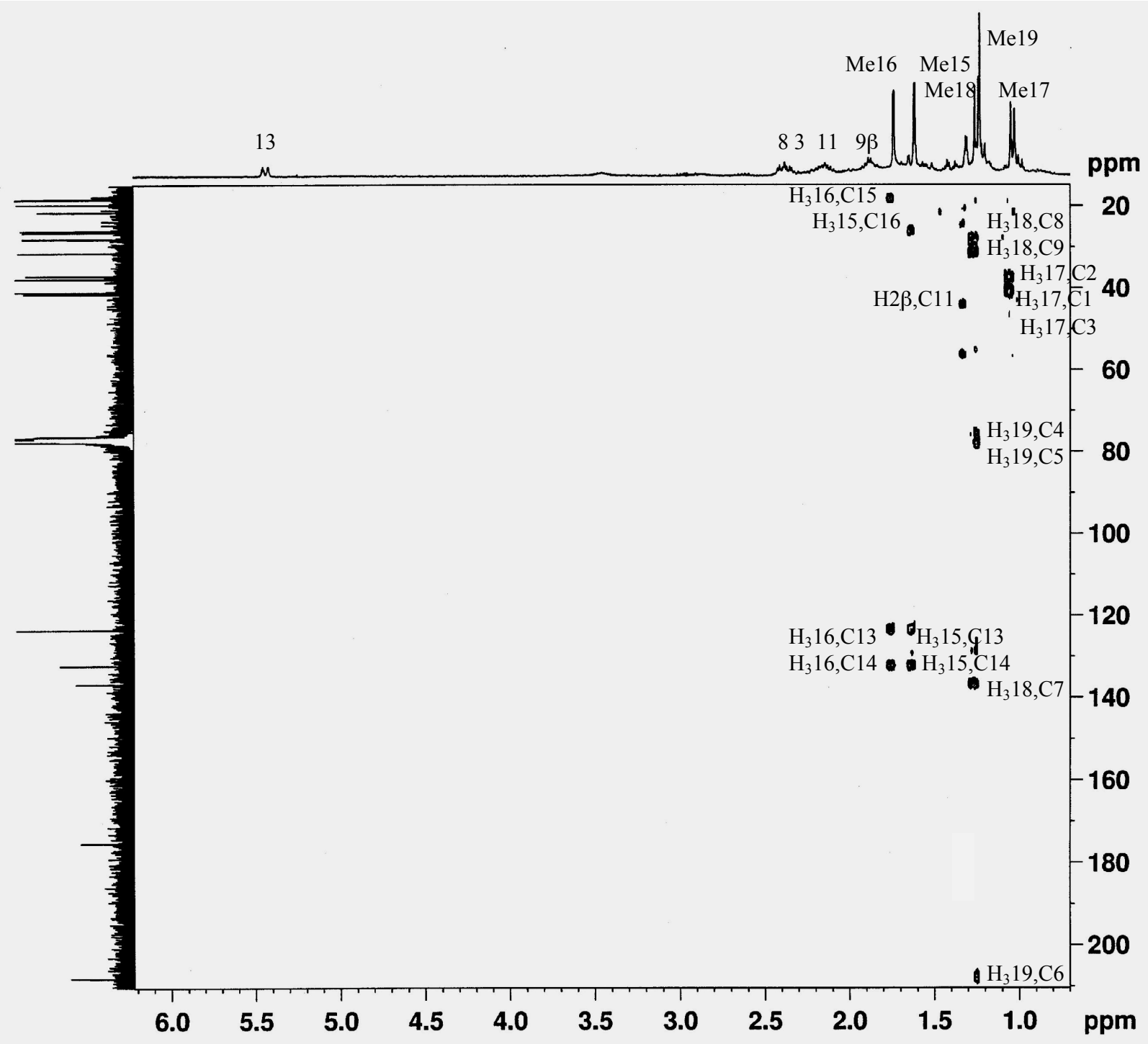




\section{NOESY Spectrum of Caribenol $\mathrm{B}$ in $\mathrm{CDCl}_{3}$}

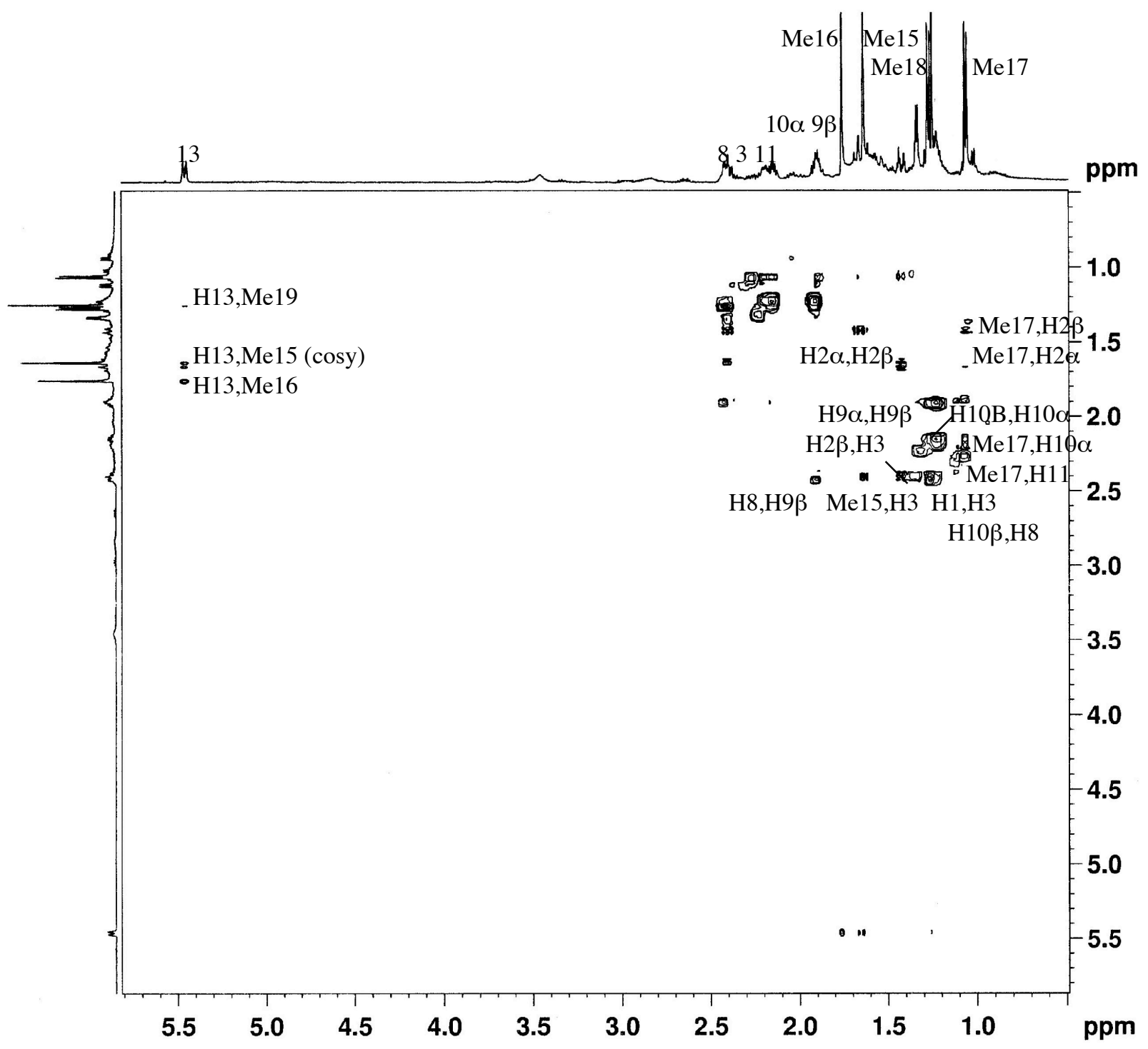

